\title{
Construction of Assistive Technology for Blind Women: Handbook on Behavioral Contraceptive Methods
}

\author{
Mariana Gonçalves de Oliveira*, Lorita Marlena Freitag Pagliuca \\ Post Graduate Nursing Program, Universidade Federal do Ceará/PPGENF/UFC, Fortaleza, Brazil \\ Email: ${ }^{*}$ marianagdoliveira@hotmail.com
}

Received 19 September 2014; revised 18 October 2014; accepted 12 November 2014

Copyright (C) 2014 by authors and Scientific Research Publishing Inc.

This work is licensed under the Creative Commons Attribution International License (CC BY). http://creativecommons.org/licenses/by/4.0/ c) (i) Open Access

\begin{abstract}
It notes the need of searching for technologies and strategies that encompass the universe to be reached, considering the peculiarities of each customer. Thus, there is a need to develop educational technologies on sexuality in accessible formats and inclusiveness to promote health to the blind people. This study aimed to describe the construction of an assistive technology for blind women on sexual and reproductive health, with a focus on behavioral contraceptive methods. This is a study of development of assistive technology on sexual and reproductive health. Results presented in two categories: 1) content and 2) appearance. The construction of educational textbooks for blind people is to facilitate the lives of these people.
\end{abstract}

\section{Keywords}

People with Visual Impairment, Contraception, Natural Methods of Family Planning

\section{Introduction}

Disability is defined as problems in body function or structure, with a significant deviation or loss of structure or psychological, physiological or anatomical function (World Health Organization, 2004). People with disabilities include those who have long-term of physical, mental or intellectual nature, which in interaction with various barriers may hinder their full and effective participation in society on an equal basis with others. There are about 650 million people with disabilities around the world (Factsheet on Persons with Disabilities, 2012), and 191 million impaired people in Brazil, of these 506.377 are visually impaired people (The Brazilian Institute of Geography and Statistics, 2009).

${ }^{*}$ Corresponding author.

How to cite this paper: de Oliveira, M. G., \& Pagliuca, L. M. F. (2014). Construction of Assistive Technology for Blind Women: Handbook on Behavioral Contraceptive Methods. Creative Education, 5, 1979-1983.

http://dx.doi.org/10.4236/ce.2014.523222 
The visually handicapped person is one who presents loss or abnormality of visual function; there are two types: low vision and blindness. Low vision is a severe decrease in the ability to see far or near, or by having a restricted visual field. Blindness is the complete loss of vision and ranks on: congenitally blind (people who have never seen); early blind (those who have lost their vision at one year and a half old); and late blind (who acquired blindness after one year of age) (World Health Organization, 2004). The focus of this study is to blind customers, which need health care equally to all people.

Blind presents difficulties in accessing health information, especially in sexual and reproductive health, as it requires different approach. Sexuality is one of the dimensions of the human being which covers gender, sexual orientation, gender identity, eroticism, emotional involvement, love and reproduction (Oliveira \& Pagliuca, 2011; Denise, 2014).

Society does not realize in the blinds the needs of emotional and sexual attachment, limiting their life chances and creating relationship of "non-person" for the development of sexuality (Maia \& Ribeiro, 2010). Blind people feel the need to talking about sexuality and have the right of access to information in ways that are understandable. This right guaranteed in the care of family planning that consisted of educational activities for selection and discussion of contraceptive methods available, aiming to free choice and responsibility on the part of the woman and/or couple (Dombrowski, Pontes, \& Assis, 2013).

There are several methods of family planning. Among contraceptive methods (MACs) (Dombrowski, Pontes, \& Assis, 2013) available, there are the behavioral methods. These are known to require individuals' periodic abstinence from vaginal intercourse during the fertile period, if one does not want to get pregnant; if desired, it is recommended to have a relationship at that time. This method depends on the recognition of ovulation and fertile period to be successfully accomplished. The main disadvantage is that it prevents sexually transmitted diseases (World Health Organization, 2013).

Behavioral methods include coitus interruptus and the awareness methods of fertility that include the basal body temperature (BBT), cervical mucus or billings, and the table of ogino-knauss. These methods, therefore, favor the exercise of autonomy.

The blind costumers present demand for information about their health condition, either on health promotion, prevention, diagnosis or treatment. One strategy used by nurses to attend in these situations is to develop educational materials, as manual.

The use of educational handbook as a help tool, based on scientific knowledge, can promote health and at the same time, make life easier for people. Reading manuals helps patients, families, and neighbors during learning and thus stimulates self-care, and makes them understand the process of health and disease. The construction of educational textbooks for promotion and health education brings important contributions as an educator and educational support for learners.

From the foregoing, it finds the need to seek technology and strategies that encompass the universe to be reached, considering the peculiarities of each customer. Development studies of assistive technology are intended to develop resources and services that will help promote independent living and inclusion of people with disabilities (Bersch, 2012).

Thus, there is a need to develop educational technologies on sexuality in accessible formats and with inclusiveness to promote health to the blind people. Given this context, the objective was to describe the construction of an educational manual for blinds on sexual and reproductive health with a focus on behavioral contraceptive methods.

\section{Method}

This is a study of development of assistive technology, in the form of an educational handbook, which describes the model-building of the manual, following concepts of universal design and assistive technology for the blind person, understanding that this is the most appropriate way to approaching its vertices.

Universal design includes projecting physical, social, and virtual environments in which all people, respecting their characteristics, may live with harmony, wellness and wholeness (Freire Jr., Arêas, Arêas, Silva, \& Barbosa, 2013). Educational materials on health respecting this principle allow people with different access requirements to benefit from the same information, facilitating human interaction.

Building an educational manual requires development of project, which includes content and appearance, understanding and integrated in successive phases. The project set up objective and target audience to be addressed, 
this junction is given the theme and content, the audience certainly explains their topic of interest (Echer, 2005).

For preparation of the contents were consulted, in a systematic way, reliable sources of scientific literature; official documents and educational materials available in health services. The materials collected were critically read, blacklisted, organized by subject and selected to integrate content; important to select the essential information. The resulting text uses clear, objective and understandable language to wide range of people. Subsequently, should be reviewed regularly to keep its content updated (Echer, 2005).

When preparing educational materials for the blind, some characteristics of appearance must be met: principles of universal design, inclusive figures, suitable sources, footnotes and physical structure (Bersch, 2012).

\section{Results and Discussion}

\subsection{Building the Manual}

The intent of Universal Design is not driving a technology only for the needy, but for all people. The goal is to promote the creation of inclusive products for people with disabilities, avoiding that feel excluded from society (Freire Jr., Arêas, Arêas, Silva, \& Barbosa, 2013). The principles of Universal Design should be followed in the construction of any educational manual. Thus, it can reach to population and not only a small portion of this, people who know braille spelling.

The results will be presented according to the construction of the technology in two categories: 1) contents and 2) appearance.

\subsubsection{Category 1: Content}

Initially, there was the identification of the target audience, made gathering information that had an interest in learning through informal conversations and interviews and the best format to addressing this issue.

At first, there was the search for the manual's content. Educational materials available on this topic in health services driven to the general population were collected. Then, was performed a bibliographic search for obtaining scientific articles and texts for theoretical background. The diversity of materials allows the selection of those considered accessible and understandable to the population to be benefited.

When selecting the contents of the manual there were valued subjects which watched the main doubts among users. The selected information should assist the customer's self-care and avoid imposing patterns of behavior and attitudes. It is deemed important to selecting the information that is really necessary to be included in the manual, because this needs to be objective, simple and direct, can be extensive and complex. It needs to be easily understood, with brief reading that encouraging people to read till the end.

The content presented sought to be well written and easy to understand, to engaging the reader and cause learning, autonomy leading to these clients to foster their decision making and thus promote health. So the contents of this manual should be planned, accurate and relevant enabling effective communication in health (Gozzo, Lopes, Prado, Cruz, \& Alameira, 2012).

It was found a notebook on primary care: sexual and reproductive health and a small notebook titled sexual and reproductive rights and contraceptive methods, both published by the Ministry of Health (MOH). Then it was decided to adapt their contents to build the manual.

The manual was divided in two parts: introduction and development. In the introduction contains the presentation, the theme and goals. The development addresses the benefits of the practice to the individual, the availability of elements, professional recommendations and scientific evidence (Gozzo, Lopes, Prado, Cruz, \& Alameira, 2012).

The contents of the manual has been exploited since the cover; later in the presentation, with elucidation of the origin of the chosen theme, the topics and objectives of the work, which are to provide information in a clear and appropriate manner to the blind people, and serve as the basis for health professionals at the time to offer advice or perform health education to that particular group. It has a summary with the list of the discussed topics, divided into sections, with their pages.

The concepts and considerations should be presented in a logical order, the information is cleared with examples and it is recommended to use only texts necessary for understanding, not use too many arguments that can confuse the reader or tire him. Use positive actions, emphasizing what should be done by the reader, and what should not be done, as well as emphasizing the benefits after reading.

In the first part, entitled "The body of the woman”, the woman's reproductive system was described, present- 
ing the female anatomy, the internal and external organs and their functions. External and internal genitals were shown in figures representing each region described. A step by step description of the exploitation of figures aimed to facilitate blind to the knowledge of what is groping and show the proper way to explore the figure to understand the subject matter.

The chapter "How to get pregnant" discusses the physiology of fertilization. In this, it describes how pregnancy occurs, when it manifests the woman's fertile period, the route taken by sperm to reach the egg and zygote formation occurs. After this explanation, it drew in ink and dotted touch the figure of the female reproductive tract, with the path that runs along the sperm to reach the egg. Understand the female reproductive anatomy and physiology is essential to understand the functionality of the behavioral contraceptives.

"Talking about contraceptives," begins the explanation of what these methods, we describe the currently existing methods and criteria to choose the one that fits the lifestyle of the reader. Thus, to proceed to the last part of the manual, you can easily understand the differential behavioral methods.

Finally, behavioral list is contraception. Presents its definition, we show the benefits and harms, about each type of behavioral method and its peculiarities is explained. For this, the text followed the order: table, cervical mucus, temperature, and method of withdrawal. In the description of each method discussed is a sub-item on the instructions and an example.

The method of table requires the observation of several menstrual cycles to determine the woman's fertile period. The adoption of this method requires discipline, knowledge of the functioning of the body and close observation of the woman. This chapter presents a model for building a tactile blind person table in a braille calendar she record the menstrual cycle. The method Cervical Mucus is based on the determination of self-fertile by observing the change of the consistency of the cervical mucus, and the sensation of dampness in the vagina throughout the menstrual cycle period. To understand the aspects of the mucus was used as an example egg that has texture like mucus.

The basal temperature is based on the changes that the female hormones cause the body temperature during the menstrual cycle for this assessment blind woman uses audible thermometer. Basal body temperature is the body temperature at rest. The withdrawal method involves the responsibility and the control of man, since it should withdraw the penis from the vagina before ejaculation. Each of these methods has its instructions for use described and accompanied by tactile figures related to each specific method.

The language used is extremely important and has to be clear and objective. Indeed, the purpose of the construction of the manual is to provide guidance to clients, families, neighbors, friends, so indispensable simple language that can be understood by everyone, regardless of the level of instruction (Echer, 2005). It limited the use of jargon, technical and scientific terms. The content and language technologies addressed in health and educational materials should be appropriate according to the needs of the audience, respecting the culture and way of life of each.

\subsubsection{Category 2: Appearance}

To understand the goal of universal design, the appearance of the manual is available in Braille and ink simultaneously. Any figure in inclusive educational material should be described, i.e., textual equivalence has thus, facilitating understanding by the visually impaired reader. Therefore the figures presented in the manual contained description in Braille and ink and preceding figures was touching explicit direction to them to understand them better. For example: "grope starting from the bottom, in the central region, which will touch the vaginal canal. Rising in the figure, will find the cervix, which separates the vaginal canal of the uterus. Further up is the uterus, which is all this central space to the top".

The use of pictorial features that convey a message can reduce communication barriers. Besides proposing readability and comprehension of text, illustration attracts the reader and explains the information (Gozzo, Lopes, Prado, Cruz, \& Alameira, 2012). The number of six figures is limited to avoid overloading. These have embossed dotted contours. This type of printing is known as thermoform, held in graphical braille specialized printing this handbook Dorina Nowill, located in São Paulo. The figures were presented in real size, to avoid bias in interpretation.

When written in ink, it used the largest and capital sources for headings, subheadings highlighted in lowercase, but in bold, white paper written in black on the cover illustration was presented showing the theme, so the reader can grasp the main message.

There were avoided header and footer notes that confused the reader, making its reading interpreting the same 
as an integral part of the content. The physical structure of the manual presented black printing on white background; cover with images and attractive colors; binding to facilitate the handling of pages; actual size of A4 paper; forty-four numbered pages, so they don't become heavy and bulky.

At the same time, writing in Braille and tactile ink and drawing figures. Thus, universal design allows the use of the manual by blind and sighted. Among the purposes of the construction of affordable manual, are: guidelines to facilitate the blind consultations by health professionals; provide support to teachers in public and private school systems; promote health through health education, work in communities; clarify the doubts of the population as a means of consultation; obtain studies and research on this subject. The manual can be used individually or in groups.

\section{Conclusion}

Educational technologies intended to facilitate the knowledge of the target population. The construction of the manual took place to facilitate the learning of the blind people about sexual and reproductive health, since that portion of the population has presented difficulty to acquire accessible information on this theme. On the other hand, it is also a way to help the work of health professionals in queries and actions of health education of family planning.

The construction of educational manuals for blind people has taken place to make the lives of these people easier. The use of educational, illustrative and instructive manual contributes to a better learning. Users can receive guidance through the manual and walk the path best suited to follow. The use of manual in the teachinglearning process has been used since the schools until health queries. Assistive technology is another tool to make life easier for people with disabilities, and provide information about health promotion and self-care.

\section{References}

Bersch, R. (2012). Assistiva tecnologia e educação. O que é tecnologia assistiva.

Denise, R. Q. S. (2014). Sex Education in the Eyes of Brazilian Public School Teachers. Creative Education, 5, $1418-1427$. http://dx.doi.org/10.4236/ce.2014.515160

Dombrowski, J. G., Pontes, J. A., \& Assis, W. A. L. M. (2013). Performance of Nurses in Prescribing Hormonal Contraceptives in the Primary Health Care Network. Revista Brasileira de Enfermagem, 66, 827-832.

http://www.scielo.br/scielo.php?script=sci_arttext\&pid=S0034-71672013000600003\&lng=e http://dx.doi.org/10.1590/S0034-71672013000600003

Echer, I. C. (2005). Elaboração de manuais de orientação para o cuidado em saúde. Revista Latino-Americana de Enfermagem, 13, 754-757. http://dx.doi.org/10.1590/S0104-11692005000500022

Factsheet on Persons with Disabilities (2012). United Nations. http://www.un.org/disabilities/default.asp?id=18

Freire Jr., R. C., Arêas, G. P. T., Arêas, F. Z. S., \& Barbosa, L. G. (2013). Study of the Accessibility of Aged People to the City Center of Caratinga, State of Minas Gerais, Brazil. Revista Brasileira de Geriatria e Gerontologia, 16, 541-558. http://www.scielo.br/scielo.php?pid=S1809-98232013000300012\&script=sci_abstract

Gozzo, T. O., Lopes, R. R., Prado, M. S., Cruz, L. A. P., \& Alameira, A. M. (2012). Information to the Development of an Educational Manual for Women with Breast Cancer. Escola Anna Nery, 16, 306-311. http://dx.doi.org/10.1590/S1414-81452012000200014

Maia, A. C. B., \& Ribeiro, P. R. M. (2010). Dispelling Myths to Minimize Prejudice about the Sexuality of People with Disability. Revista Brasileira de Educação Especial, 16, 159-176.

Oliveira, M. G., \& Pagliuca, L. M. F. (2011). Knowledge of Blind Women on Natural Contraception Methods: An Exploratory Descriptive Study. Online Brazilian Journal of Nursing, 10, 1. http://www.objnursing.uff.br/index.php/nursing/rt/captureCite/3213/0/BibtexCitationPlugin http://dx.doi.org/10.5935/1676-4285.20113213

The Brazilian Institute of Geography and Statistics (2009). Censo demográfico 2010: Características gerais da população. http://www.ibge.gov.br/home/estatistica/populacao/censo2010/default.shtm

World Health Organization (WHO) (2004). CIF: Classificação Internacional de Funcionalidade, Incapacidade e Saúde. Lisboa: World Health Organization. http://www.inr.pt/uploads/docs/cif/CIF port \%202004.pdf

World Health Organization (WHO) (2013). Sexual Health. In Health Topics. Geneva: WHO. http://www.who.int/topics/sexual_health/en/ 
Scientific Research Publishing (SCIRP) is one of the largest Open Access journal publishers. It is currently publishing more than 200 open access, online, peer-reviewed journals covering a wide range of academic disciplines. SCIRP serves the worldwide academic communities and contributes to the progress and application of science with its publication.

Other selected journals from SCIRP are listed as below. Submit your manuscript to us via either submit@scirp.org or Online Submission Portal.
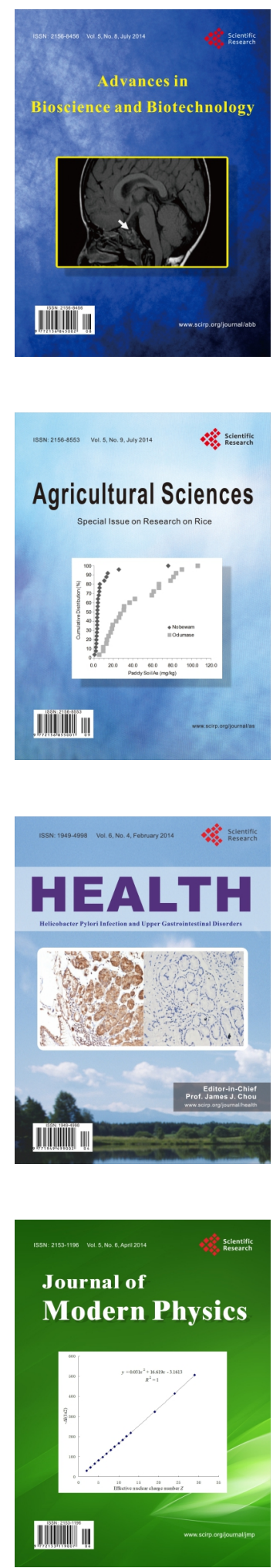
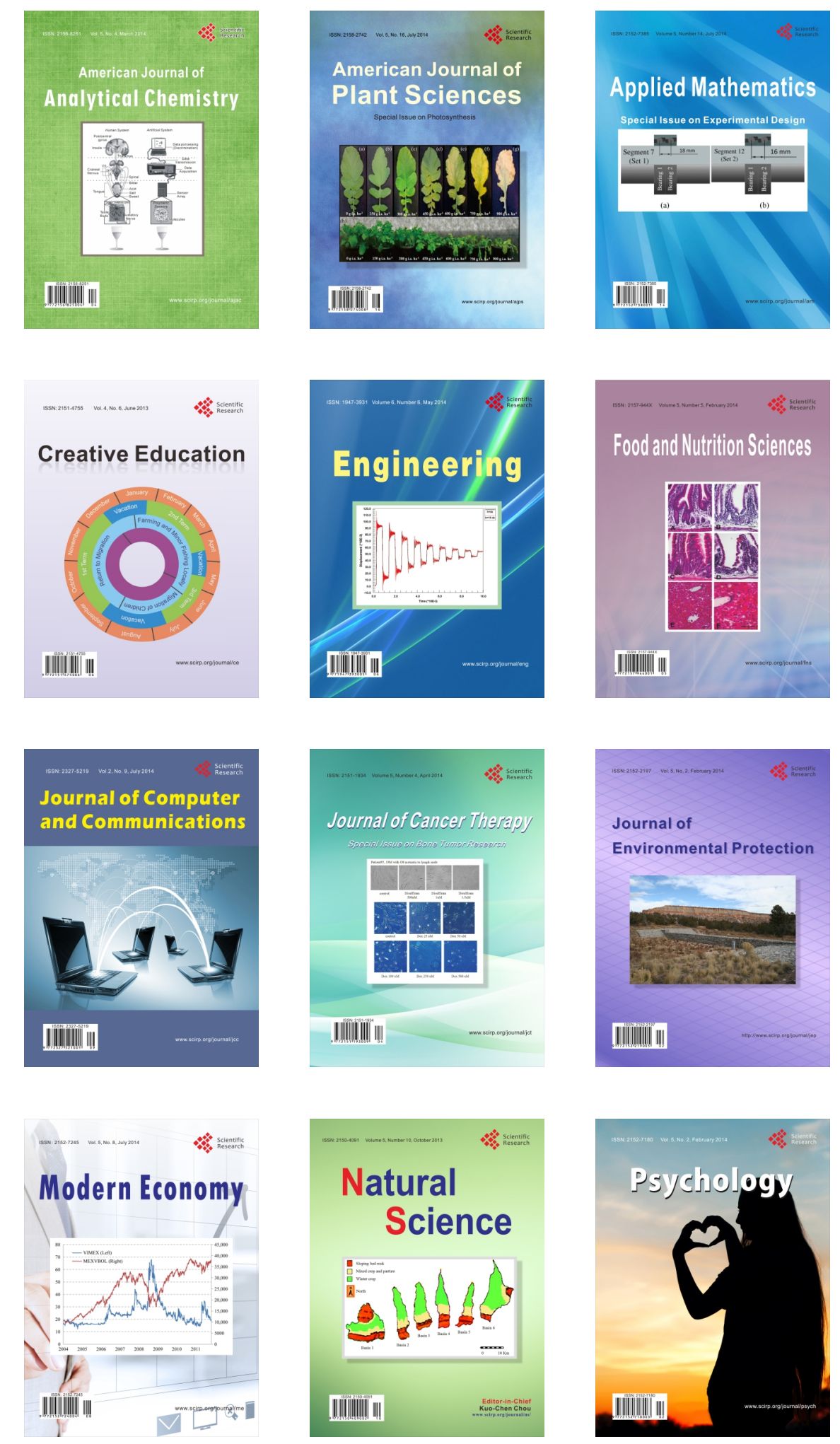